\title{
AAirman
}

\author{
Jurnal Teknik dan Keselamatan Transportasi
}

\section{Rancangan Program Robotika Marsheller di Akademi Teknik dan Keselamatan Penerbangan Makassar}

\author{
Marsheller Robotics Program Design \\ at the Makassar Aviation Safety and Engineering Academy
}

\author{
Indrawan $^{1}$, Rudy Prihatin ${ }^{2}$, La Ode Muhammad Makmun ${ }^{3}$ \\ indrawan@gmail.com, rudyprihatin@gmail.com, laodemuhammadd@gmail.com
}

Akademi Teknik dan Keselamatan Penerbangan Makassar

\begin{abstract}
ABSTRAK
Bandar udara sebagai titik simpul pergerakan pesawat membutuhkan berbagai sarana dan prasarana penunjang demi kelancaran operasional penerbangan berdasarkan regulasi yang ditetapkan pada Annex 14 tentang Aerodrome. Apron merupakan sarana pada bandar udara yang berfungsi tempat parkir pesawat, naik turun penumpang, bongkar muat barang, dan perpindahan intra dan antramoda transportasi. Sumber daya yang ahli sangat dibutuhkan agar bisa menghandling pesawat yang berada di Apron agar aktifitas pergerakan menjadi efektif dan efisien. Akademi Teknik dan Keselamatan Penerbangan (ATKP) Makassar membuka Program Diklat Marshalling untuk mencetak sumber daya yang diharapkan Kementrian Perhubungan. Tujuan perancangan ini adalah menghasilkan rancangan Robotika marshaller dalam pemanduan parkir pesawat sebagai media pembelajaran untuk memudahkan peserta diklat Marshalling ATKP Makassar dalam proses perparkiran pesawat udara pada saat menunju parkir stand hingga berhenti. Perancangan ini merupakan aplikasi Arduino Mega 2560 untuk menghasilkan simulasi kegiatan marshaller dalam pemanduan parkir pesawat sesuai dengan annex 2 tentang rule of the air. Hasil rancangan ini memberikan prespektif yang lebih mudah dipahami oleh peserta diklat dibandingkan sekedar materi yang dipaparkan di papan tulis atau powerpoint. Selain itu prespektif simulasi ini bisa dilihat dari berbagai sisi dimana posisi pesawat udara, marshaller dan marka yang ada pada Bandar udara secara sekaligus. Maka dengan rancangan ini ATKP Makassar bisa meningkatkan mutu dan kualitas sumber daya manusia para peserta diklat marshalling.
\end{abstract}

Kata kunci: robotika; marshaller; programing

\section{ABSTRACT}

Aerodrome plays the role as the node movement of aircraft which needs a various kind of facility and infrastucture's contributor for the aviation operational's flowliness based on regulation and provision which is listed on annex 14 telling about aerodrome. Apron is facility in aerodrome that has a lot of function such as for the aircraft parking, loading/unloading the passangger and stuff, and movement intra and antarmoda transportation. Qualified human resources are needed in order to be able to handle the aircraft on the apron so that movement's activity would be efficient and effective. Civil Aviation Safety and Engginering of Academi (CASEA) Makassar opens Marshalling shortcourse program to produce human resource which is wanted by Ministry fof Transportation. The objective of 
this design was producing robotic marshaller's design for guidance of aircraft's parking as the learning media to easify the student of marshalling shortcourse CASEA Makassar on process to park the aircraft to parking stand until it stops. This design was application of Arduino Mega 2560 to produe narshaller activity's simulation for aiecraft's parking guidance in accordance with Annex 2 telling about Rule of the air. The result of this design was to give an understandable perspective for the shortcourse's student instead of using material which was written down on whiteboard or slide in powerpoint. Besides that, this simulation's persepetive can be seen from various aircraft's position, marshaller and the sign on airport simultaneously. So, by using this design, CASEA MAKASSAR can improve the quality of the marshalling shortourse's student.

Keyword : robotic; marshaller; programing

\section{PENDAHULUAN}

Pertumbuhan permintaan transportasi udara secara nasional berdasarkan statistik mencapai dua digit artinya kesiapan terhadap fasilitas operasional dibandar udara tentu membutuhkan perhatian serius untuk memberikan pelayanan kepada pihak pemangku kepentingan khususnya penumpang dan operator penerbangan.

Bandar udara sebagai titik simpul pergerakan pesawat membutuhkan berbagai sarana dan prasarana penunjang demi kelancaran operasional penerbangan berdasarkan regulasi yang ditetapkan pada Annex 14 tentang Aerodrome. Apron merupakan sarana pada bandar udara yang berfungsi tempat parkir pesawat, naik turun penumpang, bongkar muat barang, dan perpindahan intra dan antramoda transportasi. Sumber daya yang ahli sangat dibutuhkan agar bisa menghandling pesawat yang berada di Apron agar aktifitas pergerakan menjadi efektif dan efisien.

Marshaller merupakan sumber daya manusia yang memiliki pengetahuan dan ketrampilan dalam memarkir pesawat (marshalling), apron dan peraturan penempatan pesawat yang akan parkir dan pergerakan pesawat di apron. Pendidikan dan pelatihan yang baik dan berintegritas dapat menghasilkan marshaller yang bersertifikat dan berstandar Direktorat Keselamatan Penerbangan Dirjen Perhubungan Udara Kementerian Perhubungan.

Akademi Teknik dan Keselamatan Penerbangan (ATKP) Makassar melaksanakan Program Pendidikan dan Pelatihan (DIKLAT) Marshalling untuk mencetak sumber daya manusia (SDM) sistem perparkiran pesawat berdasarakan SKEP 302/V/2009 Tentang petunjuk dan tata cara peraturan keselamatan penerbangan sipil bagian 139 - 11 (advisory circular casr part 139-11), lisensi personel bandar udara. Pada program DIKLAT tersebut peserta diklat belum memiliki suatu fasilitas simulasi kegiatan marshalling secara automation yang dapat digunakan sebagai penunjang pembelajaran guna meningkatkan pemahaman kondisi yang sebenarnya akan terjadi di Bandar Udara. ATKP Makassar merupakan perguruan tinggi vokasi dengan keahlian terapan dibidang penerbangan dimana terdapat diklat pembentukan Diploma III Telekomunikasi dan Navigasi Udara (TNU). Taruna Program Studi DIII Teknik Navigasi Udara dididik dan dilatih dengan mata kuliah elektronika, kontrol dan pemograman, mikrokontroler, automation, dan lain-lain sehingga bisa menyelasaikan masalah penerbangan dan menghasilkan karya untuk insan penerbangan baik dilapangan kerja maupun sebagai media sosialisasi pada pameran transportasi.

Tujuan perancangan adalah menghasilkan program dan robot dalam bentuk simulasi kegiatan marshaling secara automasi sehingga dapat digunakan sebagai salah satu media pembelajaran DIKLAT marshalling yang saat ini belum tersedia dan dapat pula ditampilkan pada pameran transportasi yang diselenggarakan oleh Kementerian Perhubungan.

\section{METODE PERANCANGAN}

Perancangan ini menggunakan metode aplikasi Arduino Mega 2560, Waktu perancangan ini dimulai pada 10 oktober 2016 sampai 10 Juli 2017 bertempat di Laboratorium Eloktronika dan komponen Akademi Teknik dan Keselamatan Makassar. Komponen komponen yang dibutuhkan dalam menunjang kelancaraan perancangan ini yaitu : Alat tulis, Laptop Lenovo Flex-2, Arduino Mega 2560, Kabel Serial, Arduino IDE, Bahasa Program C. Teknik dan Tahapan Rancangan ini terbagi 2 
yaitu Tahapan hardware adalah menyiapkan alat tulis untuk melakukan penulisan rancangan alat mengenai dimensi yang dibuat, merakit dan menyambung komponen-komponen prototype marshaller berbentuk seorang marshaller yang sebenarnya sehingga prototype marshaller tersebut bisa bergerak dan seimbang dalam melakukan pergerakan marshalling dalam memandu parkir pesawat.

Tahap Programing adalah melakukan pemberian instruksi perintah melalui bahasa program $\mathrm{C}$ melalui jendela Arduino IDE, kemudian di upload pada Arduino mega 2560 melalui Laptop Lenovo Flex-2 dengan perantara kabel serial. Output yang dihasilkan berupa gerakan isyarat tangan untuk memandu pesawat dalam parkir di Apron hingga pesawat berhenti di parking stand.

\section{HASIL RANCANGAN}

Rancangan robot marshaller terbagi atas 2 yaitu robot marshaller 1 dan robot marshaller 2. Dalam pemograman rancangan robot marshaller 1 menggunakan 6 buah servo. Pada Pemograman rancangan robot marshaller 2 juga menggunakan 6 buah servo. Masing - masing servo diletakan pada pergerakan tubuh marshaller. Masing-masing Motor servo digunakan sebagai penggerak pada sistem servo mekanis untuk menggerakan kontrol posisi lengan robot marshaller. Motor servo ini mampu bergerak 2 arah yaitu Clock Wise dan Conter Clock Wise (CW dan CCW) atau searah jarum jam dan berlawanan jarum jam. Motor servo ini memiliki sudut perputaran 180 derajat.

Robot Marshaller 1 diprogram untuk memandu pesawat udara 1 dan Robot Marshaller 2 diprogram untuk memandu pesawat udara 2 dalam parking pesawat, dalam pemanduannya robot marshaller akan memberikan aba - aba belok kiri, belok kanan, maju, dan berhenti berupa isyarat tangan. a. Flowchart Perancangan Pemprograman

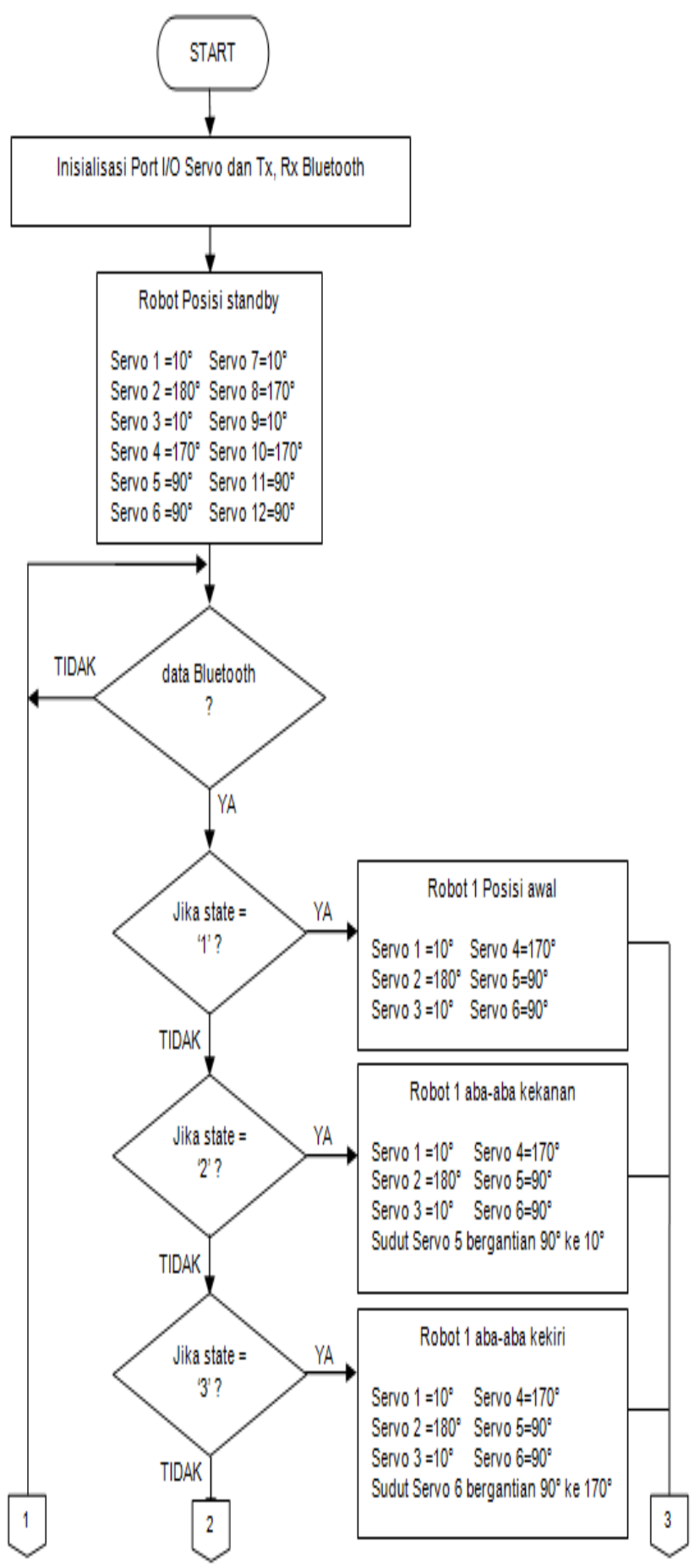




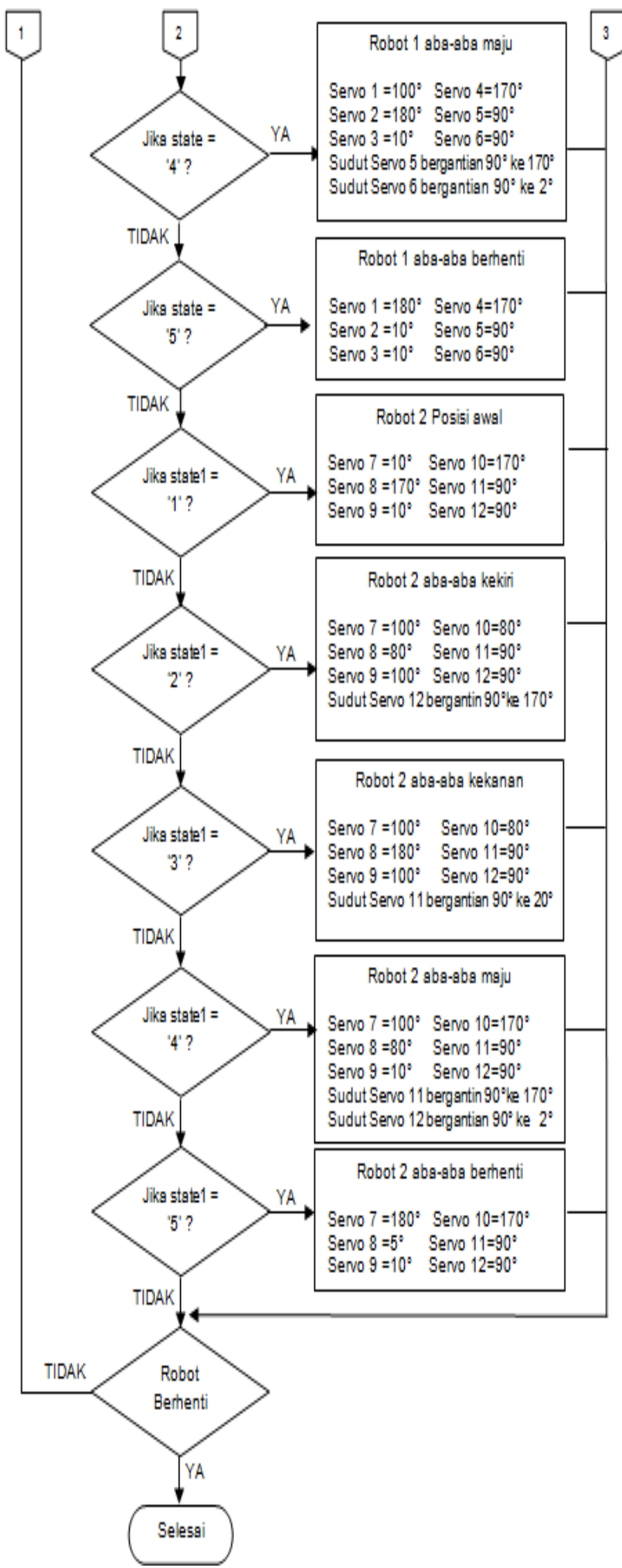

Gambar 1. Flowchart Perancangan (Sumber: Hasil Rancangan) b. Cara Pengoperasian Rancangan

Pada komunikasi ini Bluetooth master akan mengirimkan sinyal posisi pesawat udara kepada Bluetooth slave, informasi yang dikirimkan berupa posisi pesawat udara dari landing sampai berhenti di parking stand. Pada table 1 menjelaskan sinyal yang dikirim dan posisi pesawat.

Table 1. Informasi Bluetooth master

\begin{tabular}{ccc}
\hline No & Tahap & Posisi Pesawat Udara \\
\hline $\mathbf{1}$ & State & Pesawat udara 1 berada di runway \\
& '1' & menuju taxi Bravo \\
$\mathbf{2}$ & State & Pesawat udara 1 berada di taxi \\
& '2' & Bravo menuju apron \\
$\mathbf{3}$ & State & Pesawat udara 1 berada di apron \\
& '3' & menuju parking stand \\
$\mathbf{4}$ & State & Pesawat udara 1 berada di jalur \\
& '4' & center line parking stand \\
$\mathbf{5}$ & State & Pesawat udara 1 berada pada tetap di \\
& '5' & ujung parking stand \\
$\mathbf{6}$ & State1 & Pesawat udara 2 berada di runway \\
& '1' & menuju taxi Alpha \\
$\mathbf{7}$ & State1 & Pesawat udara 2 berada di taxi \\
& '2' & Alpha menuju apron \\
$\mathbf{8}$ & State1 & Pesawat udara 2 berada di apron \\
& '3' & menuju parking stand \\
$\mathbf{9}$ & State1 & Pesawat udara 2 berada di jalur \\
& '4' & center line parking stand \\
$\mathbf{1 0}$ & State1 & Pesawat udara 2 berada pada tetap di \\
& '5' & ujung parking stand
\end{tabular}

(Sumber: Hasil Rancangan)

Informasi tersebut akan diterima oleh Bluetooth slave, kemudian dibaca oleh arduino mega 2560. Program akan mengeksekusi gerakan yang akan diberikan oleh marshaller untuk memandu pesawat udara berdasarkan posisi pesawat tersebut komunikasi ini akan terus berlangsung dimana pesawat memberikan informasi posisi dan robot marshaller akan memberikan gerakan pemanduan sampai pesawat berhenti diparking stand.

\section{c. Uji Coba Rancangan}

Pada Program pemanduan pesawat udara, pesawat udara akan landing pada runway kemudian mulai berkomunikasi dengan robot marshaller. Robot marshaller akan membaca sinyal dari pesawat bahwa pesawat berada pada state1 ' 1 ' dimana pesawat sedang dalam wilayah runway menuju taxiway alpha. 
Kemudian pesawat udara akan mengirim sinyal kepada robot marshaller dimana pesawat berada pada taxiway alpha dan menuju apron, pada saat mendekati di Apron robot marshaller akan membaca sinyal state1 ' 2 ' sehingga robot marshaller memberikan panduan kekiri kepada pesawat. Sesampainya di apron robot marshaller akan membaca sinyal state1 ' 3 ' jika pesawat sudah berada di depan parking stand maka robot marshaller akan memberikan aba-aba belok kekanan. Terakhir robot marshaller akan membaca sinyal state1 ' 4 ' dimana pesawat berada pada lintasan parking stand sehingga robot marshaller akan memberikan panduan kepada pesawat untuk belok kiri jika pesawat terlalu condong kekiri dari garis tengah atau belok kanan jika pesawat terlalu condong kekanan, dan pada state ini robot marshaller akan memberikan aba-aba maju dan mempertahankan posisi bila pesawat sudah pada garis tengah parking stand. setelah tepat berada pada ujung garis tengah parking stand maka robot marshaller akan membaca sinyal dari pesawat udara bahwa pesawat berada pada state1 ' 5 ' maka robot marshaller akan memberikan pemanduan untuk berhenti. Untuk lebih jelas dapat diperhatikan pada gambar robot marshaller berikut dari pesawat udara landing sampai robot marshaller memberikan aba-aba berhenti.

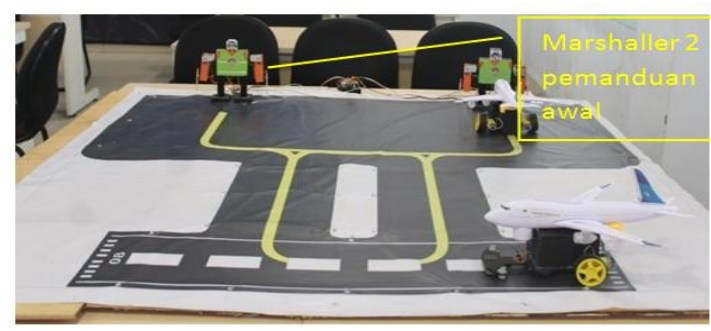

Gambar 2. Pesawat Landing

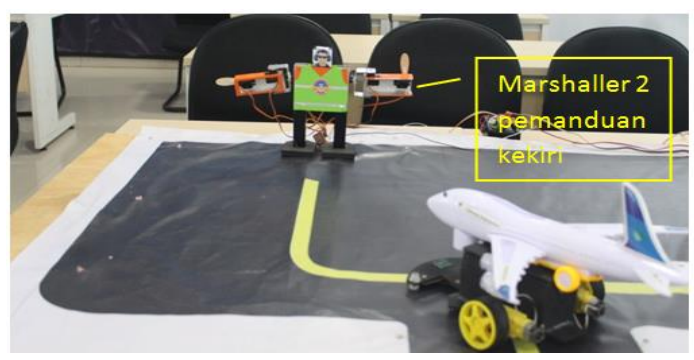

Gambar 3. Pesawat di ujung TWY A

(Sumber: Hasil Rancangan)

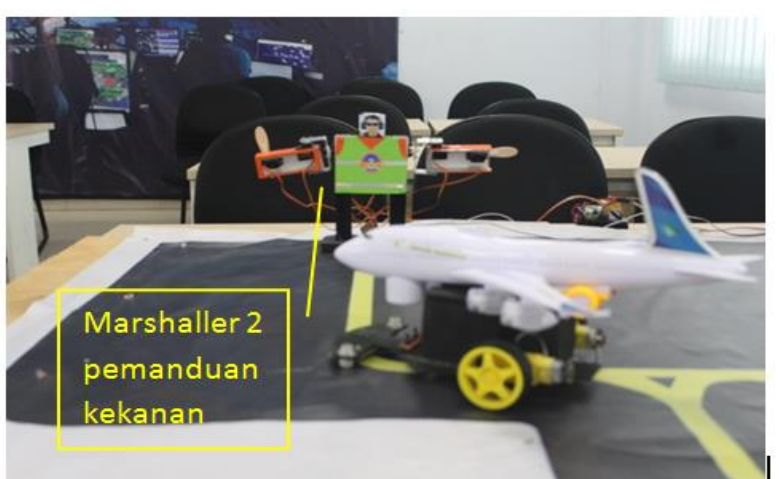

Gambar 4. Pesawat di depan Parking Stand (Sumber: Hasil Rancangan)

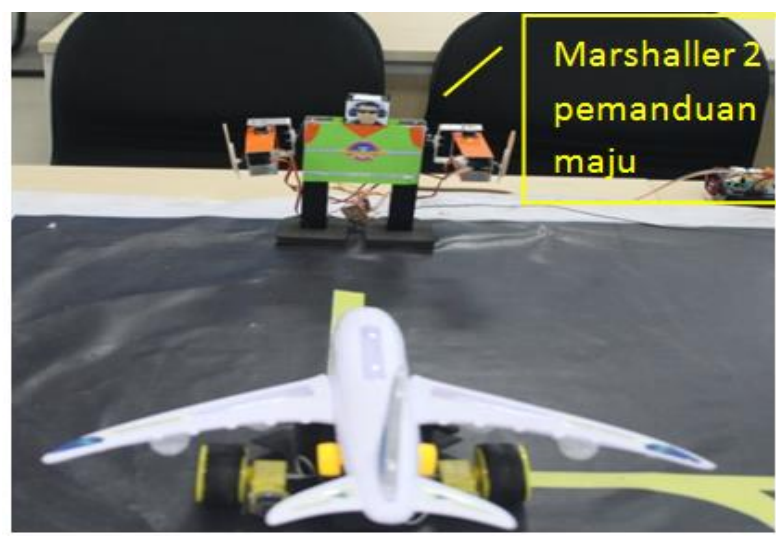

Gambar 5. Pesawat di center Parking Stand (Sumber: Hasil Rancangan)

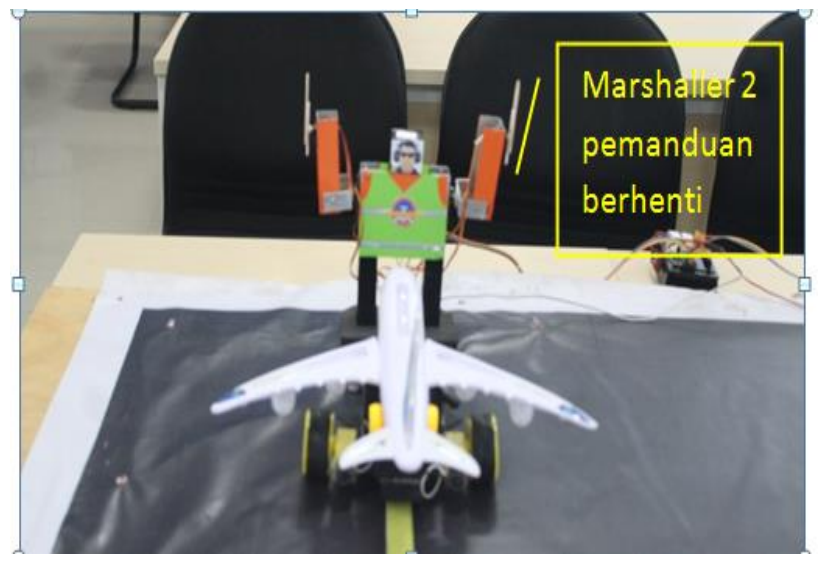

Gambar 6. Pesawat diujung Parking (Sumber: Hasil Rancangan)

Pada simulasi rancangan robotika marshaller dalam pemanduan parkir pesawat udara untuk waktu pengiriman Bluetooth master ke Bluetooth slave masing - masing pengukuran terlihat pada tebel 2 dan table 3 dibawah ini. 
Tabel 2. Waktu Kesesuaian Robot Marshaller 1

\begin{tabular}{cccc}
\hline No & $\begin{array}{c}\text { Pembacaan } \\
\text { sinyal }\end{array}$ & \multicolumn{2}{c}{ Time Record (second) } \\
\cline { 3 - 4 } & & $\begin{array}{c}\text { Pesawat } \\
\text { udara 1 }\end{array}$ & Robot marshaller 1 \\
\hline $\mathbf{1}$ & $\begin{array}{c}\text { Kondisi state } \\
\text { '1' }\end{array}$ & 05.421 & 05.000 \\
$\mathbf{2}$ & $\begin{array}{c}\text { Kondisi state } \\
\text { '2' }\end{array}$ & 09.578 & 09.520 \\
$\mathbf{3}$ & $\begin{array}{c}\text { Kondisi state } \\
\text { '3' }\end{array}$ & 14.875 & 14.739 \\
$\mathbf{4}$ & $\begin{array}{c}\text { Kondisi state } \\
\text { '4' }\end{array}$ & 21.040 & 20.567 \\
& $\mathbf{5}$ & Kondisi state \\
'5' & 22.305 & 22.239 \\
\hline
\end{tabular}

Table 3. Waktu kesesuaian Robot Marshaller 2

\begin{tabular}{|c|c|c|c|}
\hline \multirow[t]{2}{*}{ No } & \multirow{2}{*}{$\begin{array}{c}\text { Pembacaan } \\
\text { sinyal }\end{array}$} & \multicolumn{2}{|c|}{ Time Record (second) } \\
\hline & & $\begin{array}{l}\text { Pesawat } \\
\text { udara } 2\end{array}$ & $\begin{array}{c}\text { Robot } \\
\text { marshaller } 2\end{array}$ \\
\hline $\mathbf{1}$ & $\begin{array}{l}\text { Kondisi } \\
\text { state1 ' } 1 \text { ' }\end{array}$ & 05.453 & 05.156 \\
\hline 2 & $\begin{array}{l}\text { Kondisi } \\
\text { state1 ' } 2 \text { ' }\end{array}$ & 09.265 & 09.051 \\
\hline 3 & $\begin{array}{l}\text { Kondisi } \\
\text { state1 ' } 3 \text { ' }\end{array}$ & 14.562 & 14.411 \\
\hline 4 & $\begin{array}{l}\text { Kondisi } \\
\text { state1 '4' }\end{array}$ & 21.040 & 20.422 \\
\hline 5 & $\begin{array}{l}\text { Kondisi } \\
\text { state1 ' } 5 \text { ' }\end{array}$ & 22.015 & 22.009 \\
\hline
\end{tabular}

\section{KESIMPULAN}

Kesimpulan mengenai hasil dari rancangan program robotika marshaller ini yaitu:

a. Perancangan pemograman robotika marshaller mampu bekerja dengan baik, dengan indikasi implementasi pada pelaksana uji rancangan.

b. Rancangan robotika marshaller dalam pemanduan parkir pesawat udara sebagai pembelajaran terdiri dari 2 robot marshaller, 2 pesawat, sistem AFL, dan maket bandara.

c. Pemograman robotika marshaller yang saling terhubung dengan pesawat udara dan sistem AFL akan memudahkan para peserta diklat marshalling untuk memperoleh informasi tentang pemanduan pesawat udara. d. Membantu pengajar/dosen diklat marshalling dalam penyampaian materi melalui simulasi untuk meningkatkan pemahaman peserta diklat.

\section{DAFTAR PUSTAKA}

Adi, Agung Nugraha. (2010). Mekatronika. Graha Ilmu. Yogyakarta

Angkasa Pura Airport. (2013). Spesifikasi Bandara Adisumarmo, (http://adisumarmoairport.com/spesifikasi-bandara, diakses 2 November 2016)

Annex 2, Rule of the Air. (2005). International Civil Aviation Organization

Arif, Muhammad. (2016). Rancangan Teknik Industri. Deepublish. Yogyakarta

Budhiharto, Widodo, Djoko Purwanto. (2015). Robot Vision. Andi. Yogyakarta

Budiharto, Widodo. (2014). Robotika Modern-Teori dan Implementasi (edisi revisi). Andi. Yogyakarta

Departemen Perhubungan. (2011). Keputusan Direktur Jendral Perhubungan Udara nomor SKEP/302/5/2011. Direktorat Jendral Perhubungan Udara. Jakarta

Jusmin, Muh Rifai Anugrah dkk. (2015). Modul Traning Divisi Kontrol. CMCS. Makassar

Jogiyanto. (1990). Analisis Dan Desain System Informasi. Andi. Yogyakarta

Kadir, Abdul. (2015). Buku Pintar Pemograman Arduino. MediaKom. Yogyakarta

Krisnanda, Ferditya. (2014). Pengendalian Kecepatan Putaran Gas Engine Pada Rc Airplane Menggunakan Kontroler Proporsional Integral Deferensial (Pid) Berbasis Mikrokontroler Atmega 328. Jurnal Mahasiswa Universitas Brawijaya. Vol. 4 No 8:2. 
Massimo. (2014). Arduino Mega 2560.

(http://www.arduino.cc/en/Main/Ardu

inoBoardMega2560, diakses 27

Oktober 2016)

Republik Indonesia. (2009). Undang-undang no. 1 tahun 2009 tentang penerbangan. Secretariat Negara. Jakarta.

Rofiq, Muhammad, M. Yusron. (2014). Perancangan Sistem Kontrol Dan Monitoring Lampu Dengan Memanfaatkan Teknologi Bluetooth Pada Smartphone Android. Jurnal Ilmiah Teknologi dan Informasi ASIA. Vol. 8 No 1:15-16.

Suhata. (2005). VB sebagai Pusat Kendali Peralatan Elektronik. PT. Elex Media Komputindo. Jakarta. 